\title{
Negotiation: Always There and Never Called by Its Name Results From the Literature and From Empirical Experiments
}

\author{
Dr. Cherine Soliman \\ Vice Dean, Assistant Professor of Management \\ Arab Academy - Graduate School of Business, Cairo, Egypt \\ Affiliate Researcher LEMNA Research Lab, Nantes University, France \\ Email: soliman.cherine@gmail.com
}

\begin{abstract}
As reflected by a growing body of literature, conflict and negotiation have always been at the heart of our environment. One should then assume that negotiation skills have become a fundamental life knowhow. Beyond the international crisis intensification, creating complexity in conflict situations, the literature also brings evidence that conflict is an embedded dimension of every individual life. Does that mean that citizens of the world today are all equipped with the right "ready-to-use" negotiation skills? In order to investigate this question, we developed an empirical study focused on a sample of Egyptian highly educated professionals working in multinationals. We worked with 180 professionals attending an MBA program, collected data over three years, using questionnaires and word analysis. Results revealed a severe lack in negotiation education yet also gave evidence for a strong authentic need/demand. Recommendations resulting from this paper highlight the importance of including education to negotiation in the curriculum at the school and university levels. Indeed, the literature shows that good negotiation skills in highly conflictual environments will lead to business success and happy citizenship.
\end{abstract}

Keywords: Negotiation, Conflict Management, Negotiation Education.

\section{Introduction}

The global context we live in today is unique in so many ways. Over the last decades, the inhabitants of the world have witnessed a huge part of what will constitute the future of human history. The intensity of the factors which cause conflict in our environment is very high: a global consistent economic crisis, Arab springs, terrorism, tsunamis, yellow vest protests, a never ending Middle-East conflict, and the beginning of a" war for water". There is talk of an impending third world war. Some say it has already begun. All of this is happening in the context of a global pandemic.

The Covid 19, also named "Corona virus" was initially reported in December 2019 in the capital of China's Hubei Province, Wuhan. By July 20, this aggressive virus had claimed the lives of more than 600,000 people around the globe, with numbers rising by the minute.

While the World Health Organization (WHO) recommended physical distancing, closure of public spaces and testing protocols, many countries were slow to take the issue seriously.

* This article was submitted in July 2020, and accepted for publishing in August 2020.

(c) Arab Administrative Development Organization- League of Arab States, 2022, pp 385-398، 
The pandemic has aggravated an already difficult international context and has had an impact on the daily personal and professional life of hundreds of millions of people.

Indeed, on the international scene existing conflicts have not been attenuated. On the contrary, they have intensified in such contexts as Palestine, Yemen, Libya, Syria, Iran, just to name a few.

In addition, conflict at work has developed new patterns because of work-from-home stress, which includes such dimensions such as long online working experience, screen hours' stress, visual pressure, poor work life balance, poor health with limited exercise and sleep disorder. This is taking place in a context of business news announcing layoffs, downsizing and the unknown future of many large corporations with thousands of employees on their pay roll.

Conflict also hit hard the domestic environment. Families have been reporting suffering. Unpreparedness for the long months of staying at home has increased domestic violence towards children and spouses. It has also increased mental health challenges and aggravated life at home.

With no prior notice, citizens of the world have found themselves in a new era of conflict. They are new in types and intensity, at home, like at work, like on the social media and the news.

In this context, negotiation skills are essential. How prepared we were to apply negotiation skills will make a difference on how this new reality is managed in an optimal way.

In this context, this article studies to what extent negotiation education had found its place in Egypt, within the Cairo Business Community ( $C B C$ ). We studied the $C B C$ in previous research, justified by Egypt's past and present central position in history, strategically working to rebuild its economy, global political position, reconstructing its infrastructure and creating a better future after the Arab spring event of 2011.

In order to investigate we started with the literature to identify the fundamentals and foundations of conflict and of negotiation, which emphasize on the reality of conflict in human life, and the particular value of negotiation, with or without a crisis. Section one reviews the literature on conflict in human life. Section two identifies the whats and whys of negotiation. Section three is dedicated to understanding the social dilemma. Section four presents our methodology and field work. Section five presents our results, and then we conclude with the recommendation, limitations section and future research perspective.

\section{Section 1. Conflict in Human Life}

Why do people find themselves in need to negotiate? This is how we choose to start this paper. What do we mean by conflict, or how can we define conflict?

In the following paragraphs we focus our attention on work by Rubin (1994); Deutsche (1973); Fisher (1991); Burton (1997), and Lax and Sebenius (1986). Defining conflict was not an easy task as there are many definitions to choose from in the literature; eventually we referred to the one by Rubin et al. (1994) for its simplicity and exactitude: "conflict means perceived divergences of interest, or a belief that the parties' current aspirations cannot be achieved simultaneously".

Two words stand out, interests and aspiration for which we turn to work by Burton (1979). When discussing interests in his book he writes, "We mean most general people's feelings about what is basically desirable. We use them where others use value or needs. Interests tend to be central to people's thinking and action, forming the core of many of their attitude, goals, and intentions".

"Like conflict, interests have several dimensions that can be used to describe interests; to Rubin some interests are virtually universal (such as the needs for security, identity, social approval). Other interests are specific to certain actors. Some interests are more important than others, and such priorities differ from 
person to person. Before a party's interests can clash with those of others, these interests must be translated into aspirations".

Here the term aspiration appears which "in its turn, has several sources, the achievement of the other, the perceived power relation between the parties, past experience and social norms. Conflict exists when a party sees its own and the other's aspiration as incompatible" (Rubin, 1994).

So far, we defined conflict and tried to understand what it is really about by expanding on its definition.

To complete the picture, we would like to point out the existence of many different types of conflict. To cover this topic, we referred to the work of Deutsche (1973). We summarized a first typology of conflict from his work, presented in table 1.

\section{Table (1), Conflict Typology, Deutsche (1973)}

\begin{tabular}{|c|c|}
\hline Type & Description \\
\hline 1 veridical conflict & this type of conflict exists objectively and is perceived accurately \\
\hline 2 contingent conflict & $\begin{array}{l}\text { here the existence of the conflict is dependent upon readily rearranged circumstances, but this is } \\
\text { not recognized by the conflicting parties }\end{array}$ \\
\hline 3 displaced conflict & here the parties in conflict are, so speaking, arguing about the wrong thing \\
\hline 4 misattributed conflic & $\begin{array}{l}\text { in this type, the conflict is between the wrong parties and, as a consequence, usually over the } \\
\text { wrong issues }\end{array}$ \\
\hline 5 latent conflict & this is, in effect, a conflict that should be occurring but is not \\
\hline 6 false conflict & this is the occurrence of conflict when there is no objective basis for it \\
\hline
\end{tabular}

In addition, each of the different types of conflict presented in table 1 can be described according to different variables. They are identified by the same author and are presented in table 2.

\section{Table (2), Conflict Differentiation and Description Variables, Deutsch (1973)}

\begin{tabular}{|c|c|c|}
\hline & Variables & Details \\
\hline 1 & $\begin{array}{l}\text { the characteristics of the par- } \\
\text { ties in conflict }\end{array}$ & $\begin{array}{l}\text { their values and motivations; their aspirations and objectives; their physical, intellectual, } \\
\text { and social resources for solving conflict; their beliefs about conflict, including their con- } \\
\text { ceptions of strategy and tactics; and so forth }\end{array}$ \\
\hline 2 & $\begin{array}{l}\text { Their prior relationship to one } \\
\text { another }\end{array}$ & $\begin{array}{l}\text { their attitudes, beliefs, and expectations about one another, including each one's belief } \\
\text { about the other's view of him, and particularly the degree of polarization that has oc- } \\
\text { curred on such evaluation as "good-bad", "trustworthy-untrustworthy" }\end{array}$ \\
\hline 3 & $\begin{array}{l}\text { The nature of the issues giving } \\
\text { rise to the conflict }\end{array}$ & its scope, rigidity, motivational significance, formulation, periodic, etc. \\
\hline 4 & $\begin{array}{l}\text { The social environment with- } \\
\text { in which the conflict occurs }\end{array}$ & $\begin{array}{l}\text { the facilities and restraints, the encouragements and deterrents it provides with regards } \\
\text { to the different strategies and tactics of waging or resolving conflict, including the nature } \\
\text { of the social norms and institutional forms for regulating conflict }\end{array}$ \\
\hline 5 & $\begin{array}{l}\text { The interested audience to the } \\
\text { conflict }\end{array}$ & $\begin{array}{l}\text { their relationship to the parties in conflict and to one another, their interest in the conflict } \\
\text { and its outcomes, their characteristics }\end{array}$ \\
\hline 6 & $\begin{array}{l}\text { The strategy and tactics em- } \\
\text { ployed by the parties in the } \\
\text { conflict }\end{array}$ & $\begin{array}{l}\text { in assessing and/or changing one another's utilities, disutility's, and subjective proba- } \\
\text { bilities; and in influencing the other's conceptions of one's own utilities and disutility's } \\
\text { through tactics that vary along such dimensions as legitimacy-illegitimacy, the relative } \\
\text { use of positive and negative incentives such as promises and rewards or threats and pun- } \\
\text { ishments, freedom of choice and so on }\end{array}$ \\
\hline 7 & $\begin{array}{l}\text { The consequences of the con- } \\
\text { flict to each of the participants } \\
\text { and to other interested parties }\end{array}$ & $\begin{array}{l}\text { the gain of losses relating to the immediate issues in conflict, the precedents established, } \\
\text { the internal changes in the participants resulting from having engaged in conflict, the } \\
\text { long term effects on the relationships between the parties involved, the reputation that } \\
\text { each party develops in the eyes of the various interested audiences }\end{array}$ \\
\hline
\end{tabular}

The conflict types and descriptors identified by Deustche provide already quite a rich vocabulary to describe different types of conflicts. 
The literature also challenges our perceptions by suggesting the co-existence of cooperation and competition in the organization. It also confirms the importance and value of this co-existence on organizational performance. When we turn to conflict and organization, another part of the literature surprises us again with a typology distinguishing between "constructive conflict" and "destructive conflict" which enriches the work of Deustch.

On one hand we have constructive conflicts which prevents "stagnation,] ... [ stimulates interest and curiosity, it is the medium through which problems can be aired and solutions arrived at, it is the root of personal and social change. Conflict is often part of the process of testing and assessing oneself and, as such, may be highly enjoyable as one experiences the pleasure of the full and active use of one's capacities. In addition, conflict demarcates groups from one another and thus helps establish group and personal identities; external conflict often fosters internal cohesiveness. Conflict within a group frequently helps to revitalize existing norms; or to contribute to the emergence of new norms"(Deutsche, 1973, p. 9)

While at the same time, and on the opposite side it also does "Weaken the society. When people deal with conflict by contending, each trying to do well at the other's expense, they tend to engage in a set of moves and countermoves that intensifies conflict. We refer to this increase in intensify as escalation. Although conflict need not be destructive in its consequences, when it is bad, it may well be horrid. And cause so much damage to the people who are caught in its machinery" (Rubin, 1994, p. 9)

Good or bad, conflict needs to be managed. Agreements need to be reached. Based on what the literature suggested: "There are four major reasons for the emergence of stalemate: failure of contentious tactics, exhaustion of necessary resources, loss of social support, and unacceptable costs". Rubin, (1994)

"Stalemate is the stopping point in the process of push and counter push. This opens the door to negotiation" (Rubin, 1994, p. 156).

\section{Section 2. The Whats and Whys of Negotiation}

To recapitulate, people interact to achieve goals. They want different things in different ways, and times. This results in many conflicts. Be they destructive or constructive they need to be managed, solved and agreements need to be researched. For this the literature suggests negotiation.

To negotiate, in Latin, is to "carry business". Negotiation is the proposed mean for people to manage their differences. Whether these differences are manifested at work, at home or in the streets; impacting relations with their spouse, children and as well colleagues and neighbors; disabling decision making about vacation plans, financial plans, budgets, contracts or even office space distribution. In other words, "negotiation is a fact of life" (Fisher, 1991). Negotiation is a way of living life.

Like conflict, which we presented above, negotiation is a complex concept. It is the result interaction between people; and with people comes the same tension, between cooperation and competition, as in organizations (which are made up of people that interact based on rules decided by the organization).

As mentioned by Lax et al (1986, p.29-30) "Negotiation includes cooperation and competition, common and conflicting interests. In fact, it is typically understood that these elements are both present and can be disentangled. Deep down, however, some people believe that the elements of conflict are illusory, that meaningful communication will erase any such unfortunate misperceptions. Others see mainly competition and take the cooperative pieces to be minimal. Some overtly acknowledge the reality of each aspect but direct all their attention to one of them and wish, pretend, or act as if the other does not exist. Still others hold to a more balanced view that accepts both elements as significant but seeks to treat them separately. A deeper analysis shows that the competitive and cooperative elements are inextricably entwined. In practice, 
they cannot be separated. This bonding is fundamentally important to the analysis, structuring, and conduct of negotiation. There is a central, inescapable tension between cooperative moves to create value jointly and competitive moves to gain individual advantage. This tension affects virtually all tactical and strategic choices? Analysts must come to grips with it; negotiators must manage it."

This takes us to the second level of negotiation introduction regarding two large groups of strategies: distributive negotiation and integrative negotiation.

On one hand there is distributive negotiation; defined by Harvard (2003) as follows "the issue in a distributive negotiator is who will claim the most value. Some people refer to this type of negotiation as zero-sum or constant sum negotiation. The term win-lose is probably more representative of what is involved. In purely distributive negotiation, the value at stake is fixed, and each side's goal is to get as much of it as possible. Relationship and reputation mean little in the tug of war: the negotiators are not willing to trade value in the deal for value in their relationship with the other side. Information plays an important role in this type of negotiation. The less the other side knows about your weaknesses and real preferences, and the more it knows about your bargaining strength, the better will be your position." This refers to a style of negotiation that we will label as competitive.

While on the other hand there is integrative negotiation where: "the parties cooperate to achieve maximum benefits by integrating their interests into an agreement while also competing to divide the value. In integrative negotiation, you have to be good at both creating value and claiming it. Many use the term winwin in referring to this type of arrangement. Unfortunately, that term implies that all parties get everything they want, which is rarely the case. More likely, each makes tradeoffs to get the things that they value the most, while giving up other, less critical ones. Sometimes, the two sides' interests do not compete at all. In these cases, the task is to arrive at a deal that integrates their interests as efficiently as possible." (Harvard, 2003). This refers to a style of negotiation that we will label as cooperative.

The above constitute the two broad types of negotiation strategy/orientation in the simplest way. It is also important to highlight that the literature confirms that there is no pure cooperative or pure competitive negotiation. The negotiator tends to overlap between both styles creating a continuum of tension, which is referred to as the "Negotiator's Dilemma", in which the individual, while negotiating, at every moment, is making a decision asking himself in an intimate monologue: should I compete for a maximum gain? Or should I cooperate for the benefit of all? What would I gain in the second scenario? And what do I have to lose in the first one?

The literature invests enormously in explaining the general meaning of the dilemmas as well as developing their specific applications.

From the literature, we understood that this questioning is a human reality. It is the source of the "negotiator's dilemma", of conflict within the organization, due interaction between people who strive to manage their interests and aspirations. The negotiator's dilemma is a subcategory of a wider range of social dilemmas, which we will now review.

\section{Section 3. Understanding Social Dilemmas}

To better understand social dilemmas, we thought interesting and suitable to provide a panoramic summary of the concept. What are they? Why do they exist? What is the common point between them?

What we offer here is a minimum, simply an introduction to the wider concept of social dilemma. We found appropriate to start this section with a definition to the concept for which we referred to the work of Kollock (1998) "Social dilemmas are situations in which individual rationality leads to collective irrational- 
ity. This is reasonable behavior, which leads to a situation in which everyone is worse off than they might have been otherwise. Many of the most challenging problems we face, from the interpersonal to the international, are at their core social dilemmas".

When applied to the organizational context, this explanation suggests that the "wellbeing of the organization is in danger".

Hence, when the individual, in the organizational setting, favors distributive negotiation (competition) securing and maximizing his/her independent sole winnings the collectivity suffers the expense. In this context by collectivity, we refer to the entire organization, as a group of people working together toward to achieve common goal. In such a context, literature supports with evidence, that the organization will be running multiple risks. From negative work relationships to high conflict intensity environment all together leading to negative organizational performance.

Simply put, this dilemma can be defined as the tension between cooperation and competition. More elaboration will follow in the next sections.

"The literature on social dilemmas revolved around three metaphorical stories that have assumed mythic proportions. These stories - the Prisoner Dilemma, the problem of providing Public Goods, and the Tragedy of the Commons - have served as catalysts facilitating and structuring research. Social dilemmas can be narrowed down to "dilemmas that involve only two actors (known as dyadic or two person dilemmas: Prisoner Dilemma; Assurance Game; Chicken Game), and dilemmas involving multiple actors (known as N-person dilemmas, where N is some number greater than two (the Public Good dilemma; the Commons dilemma)". (Kollock,1998).

With regards to our work, and based on the above, we would like to point out that we are focusing on two-actors-only dilemmas. We now turn to the prisoner's dilemma, which is an illustration of this category. It also enables us to link this type of social dilemma with the negotiator's dilemma, which is at the heart of our paper.

\section{The Prisoner's Dilemma}

This sub section is only a demonstration of the dilemma concept in one of its very famous application, to enable to shed the light on the advantages and disadvantages of cooperation and competition, individually and in interaction.

According to Soliman et al. (2016), "the basic problem occurs when the pursuit of self-interest by each leads to a poor outcome for all. The very famous representation available is the prisoner's dilemma". To elaborate we refer to the work by Axelrod (1984), as mentioned by Soliman et al. (2016) "In the Prisoner Dilemma game, there are two players. Each has two choices, namely cooperate or defect. Each must make the choice without knowing what the other will do. No matter what the other does, defection yields a higher payoff than cooperation. The dilemma is that if both Table (3), Summary of Prisoner's Dilemma Outcomes, Axelrod (1984) defect, both do worse than if both had cooperated. As illustrative example: A district attorney know that two prisoners are indeed guilty of a crime, he doesn't have acceptable evidence to convince a jury. The alleged criminals know this. The district attorney presents the following choice problem to each of the prisoners separately. The prisoners are kept separated. Each is given the choice of not confessing or confessing." The game is summarized in table 3.

\begin{tabular}{|c|c|c|}
\hline \multicolumn{3}{|c|}{ Player One } \\
\hline & $\begin{array}{c}\text { Cooperate Not } \\
\text { Confess }\end{array}$ & Defect Confess \\
\hline 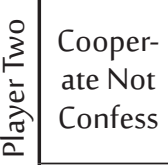 & $\begin{array}{l}\text { (1 year, } 1 \text { year) } \\
\text { R - } 3 \text { R - } 3 \\
\text { Reward for mutu- } \\
\text { al cooperation }\end{array}$ & $\begin{array}{l}\text { (5 years, } 0 \text { years }) \\
\mathrm{S}=0, \mathrm{~T}=5 \\
\text { Sucker payoff Temp- } \\
\text { tation to defect }\end{array}$ \\
\hline $\begin{array}{l}\text { Defect } \\
\text { Confess }\end{array}$ & $\begin{array}{l}\text { (0 years, } 5 \text { years }) \\
\mathrm{T}=5, \mathrm{~S}=0\end{array}$ & $\begin{array}{l}\text { (3 years, } 3 \text { years) } \\
P=1, P=1 \\
\text { Punishment for } \\
\text { mutual defect }\end{array}$ \\
\hline
\end{tabular}


Table 3 introduces the idea that if you try to maximize your personal gains by competing versus a cooperative opponent; it also shows that cooperation from both parties is the best outcome for mutual gain. However, if your initiate cooperation and if it is not reciprocated, you end up with the worst outcome.

This is the problem with cooperation, if you are the only side cooperating you lose.

Leaving, the individual wonder: while cooperation is the best strategic choice for common interest, competition seems to be not only the way to maximize individual interest but also to protect yourself from your opponent's choice of non-cooperative strategy deployment.

\section{The Negotiator's Dilemma}

Having seen the above, we can now get more specific in the field we intend to focus on. We turn to the negotiation application of the prisoner's dilemma essence in "The Negotiator's Dilemma".

Based on the literature, in negotiation negotiators either create value or claim it. Let us explain what we mean and what are the implication for the negotiators dilemma.

According to Lax (1986), on one hand "In the value-creating view negotiators work primarily to increase the available resources, to find joint gains or "win-win" solutions, wherein all the parties will benefit. Negotiators must act cooperatively, and successful negotiators are open and creative. They share information, communicate clearly, maintain a cooperative attitude and focus on developing common interests".

On the other hand, still according to Lax "In the value-claiming view negotiators work primarily to claim the largest share of the disputed goods. To be successful negotiators must engage in hard bargaining; they must "start high, concede slowly, exaggerate the value of concessions, minimize the benefits of the other's concessions, conceal information, argue forcefully on behalf of principles that imply favorable settlements, make commitments to accept only highly favorable agreements, and be willing to outwait the other fellow."

The tension between cooperative value-creating strategies and competitive value-claiming strategies is the Negotiator's Dilemma. This dilemma, as we will explain below is closely related to the famous prisoner's dilemma.

Based on Lax and Sebenius (1986), the Negotiator's Dilemma can be summed-up as follows:

1- If the two parties who are negotiating cooperate, they may obtain a GOOD outcome for each party

2- If only one party choses to cooperate while the other one competes, the competitive party will WIN and the cooperative party will LOOSE

3- If both parties involved in the negotiation compete then they both obtain a MEDIOCRE outcome.

Consequently, both parties should be better off if they cooperate. However, uncertainty has to be taken into account. None of the parties involved can be sure of their opponent's strategic decision. Each one is exposed to the danger of an unreciprocated cooperation and thus, takes the risk of losing.

But should one really compete when it is demonstrated that cooperation brings a better outcome?

According to Lax (1984) "acting on a rational calculation of their individual best interests' causes the parties to forego cooperative gains, and actually leaves them worse off than they could have been. In real negotiations, these choices present themselves at each stage, and the line between creating and claiming tactics is not clear-cut. The authors suggest that the negotiator's dilemma can be seen as a metaphor for understanding the general tension between cooperative and competitive strategies". 


\section{Conclusions Drawn From the Review of Literature}

To summarize, the literature states that conflict is real. That we are all negotiating, we all negotiate all the time. Yet are all members of society conscious of this reality and of the ubiquity of negotiation? This has implications for education in such fields as mathematics, science, writing and presentation skills. While certain societies learned the lesson and worked on incorporating negotiation education, first in continuous education, professional training and then one step further, in university curricula (starting with business schools, political science schools as well as social science degrees, and moving on to engineering, in medical and post graduate studies). Some countries, particularly in Canada and the USA, are introducing negotiation and mediation (which is an assisted negotiation) as a curriculum, as well as a practice of conflict management at primary and secondary school levels (Bluon 2005, Chittonran 2010, Cunningham et. al 1998, Gauley 2006, Haft et al 1998, IREX 2013). We even found a study by Tupper (2009) of "high school students] who negotiate school spaces beyond the classroom within a broader context of citizenship education and identity construction".

Our objective is to investigate this issue in a particular context that has always been at the center of our interest and support, which is the Egyptian context.

It is our assumption that even societies that do not give proper attention to negotiation education have an authentic need. It could very easily be addressed with the introduction of a new curriculum. We also believe that a fundamental aspect of preparing the future generation for a never-ending complex global environment is to provide it with proper conflict management skills. Thus, it is crucial and obvious to give attention to negotiation, as a science, as a discipline, which targets all the segments of the population.

In order to investigate how and by whom the need for negotiation is expressed, we developed a fieldwork design, which we will present in the next section. We aim to test the presence of negotiation and the need for negotiation education among a sample of well-educated professionals in the Egyptian business environment with the objective of generating recommendations to enhance the citizens of Egypt's experience with conflict in life.

\section{Section 4. Methodology and Fieldwork}

Our work focused on the individual's perception and positioning in the practice of negotiation by analyzing the words they use when answering questions about negotiation. The foundation in the literature review insists and supports the fact all individuals are constantly negotiating, conducting ordinary negotiations or professional/planned negotiations.

Yet are individuals aware of the negotiation context/situation? In some environments negotiation is a well-defined education and business activity enabling a society-wide understanding of the concept. Other environments are still behind on negotiation understanding and education positioning their act of negotiation under different labels. This practice might be at the base of a poor negotiation performance leading to profound negative results on the personal as well as professional context. The assumption is that even if negotiation is a universal factual practice, the lack of formal negotiation education leaves members of society unaware that they are negotiating and in full obscurity about practice, results and evaluation.

In order to test this assumption, we performed an empirical study on multiple groups of professionals. A qualitative search based on questionnaires and an analysis of the words used in the answers. Data was collected over 3 years (2016-2019) with small groups of 20 to 25 professionals at a time: all in all, 8 groups, totaling 180 people were involved. We now turn to a presentation of the fieldwork design. 
The selected populations were all MBA students (master of business administration), general characteristic summarized below in table 4.

The population studied shares a common career and education aspiration. Yet we have an interesting industry diversification representation, as well as career advancement diversification in the sample. The age group distribution reflects that we have a diversity of hierarchical positions, from entry-level non-managerial professional activity, to senior management position. Data was collected over a period of 3 years, from a particular course that is offered twice a year, fall and spring, from 2016 through 2019. Classes of 20 to 25 participant, eight classes, for which we provide consolidated results. We divided the 180 participants into two groups. A group of 160, with no prior negotiation training, which we will refer to as population $A$; and a group of 20 participants, representing $12 \%$ of the sample population, with prior negotiation training provided by the author earlier in their curriculum. They will be referred to as population B.

It was important to separate population A from population B in order to avoid prior education bias in our analysis.

The questions used were originally brainstorm material prior to introducing a chapter on communication, conflict and negotiation in a "Contemporary Management" MBA core course. It was taught during the first semester of the students in the MBA. The answers, the hesitation, the confusion that resulted from the students trying to answer the questions were the reason why we wanted to investigate the answers. In figure (1) we list the questions given to the students before the intended chapter was discussed.

Students were requested to take 15 minutes to answer these questions in class. Then we started the lecture by discussing their answers and moving to the chapter content.

Having these questions prior to the lecture, in a controlled environment, stimulated the students/participants' self-positioning in negotiation knowledge and practice. Simply terminology and words used in their expression gave us an insight of their capabilities and limitations. It is important to mention that these questions were fully discussed after collecting their answers and before we started the lecture content. The main objectives from the questions can be listed as follow:

1- Separate those with prior negotiation training or experience from those without? With the objective of:

a- Estimating how many people had prior access to this particular type of education?

b- Compare and consolidate results according to different variables

2- Estimate their level of understanding of negotiation in terms of terminology, context, types if ever.

3- When they talk about negotiation, without using this word, what other words do they use? 


\section{Section 5. Results}

Results from the questions and the wording analysis complemented one another. Having controlled the participants' original negotiation knowledge through question one has helped us distinguish the results of population A from population B, analysis results summaries in table (5) below.

\section{Population A}

Population A represents $88 \%$ of the participants in this sample compiled over three years. Here are a few examples of the answers obtained.

Question 3.a: Only 2\% of the participants stated that negotiation is a conflict resolution method applicable to all conflicts situations in a person's life. $98 \%$ of the population, after hesitation correlated negotiation to contracts and deals agreements, within the formal setting of business senior management context. Sample of words collected in table (6).

\section{Table (6), Words Used to Describe Negotiation}

\begin{tabular}{lc}
\hline Question 3.a. & What is Negotiation? \\
\hline Words used & $\begin{array}{c}\text { Disagreement management; reaching agreement; } \\
\text { concluding a contract; Win win, deals, contact }\end{array}$ \\
\hline
\end{tabular}

When discussing the answers to this question with the participants, we observed many hesitations. Many of the respondents did not understand that they actually had learnt negotiation skills through their years of practice. They had hesitations in correlating their activities to negotiation and were unconscious of the fact that they actually were negotiators on a daily basis, despite of what the literature says on the subject.

Question 3.b. This particular question usually starts raising doubts about how the respondents define negotiation. A list of the words used to answer this question is presented in table 7.

\section{Table (7), Words Used to Describe Who Conducts Negotiation}

Question 3.b. In your opinion, who conducts negotiations? Words Managers, leaders, senior managers, in business

$55 \%$ of population A supported the idea that negotiation is for managers only, a functional requirement for them; $35 \%$ replied that it a concerns the life of organizations only. Only $10 \%$ came with the deduction that "everyone is a negotiator", that "most life situation are negotiations". Discussing this with the respondents led them to open their eyes as to what negotiation really is. They became more involved. A level of self-projection and self-integration with this revelation creates an intense need for participation and a personal interest in the discussion.

We now move on to the question 3.c, sample of words summarized below is table 8 .

This question was multi-purpose, with the objective of reaching a conclusion at the end of the lecture that, for all of the above, negotiation skills apply. However, in the answers to this question the word negotiate/negotiation is only used in relation to the professional context, and only for a minority of respondents. We were always surprised that the word "negotiation" almost never came to the mind of the respondents, leading to a situation of "absent minded negotiators". It is very interesting to note that all the other words that were used as a substitution, are components of a negotiation process or outcome, such as: win-win, win-lose, relationship, the other, mutual agree-

Table (8), Words Used to Describe Situations of Disagreement

\begin{tabular}{l} 
Question How do you manage situations of disagreement? \\
a. Family context \\
b. Work context \\
c. Errands and personal context \\
\hline Words \\
a. Discussions, debates, fights, authority, power, \\
accommodate, compromise \\
b. Negotiate, compromise, agreements, win-win \\
c. Bargaining...
\end{tabular}


ment; yet the respondents do not associate it with the idea of negotiation and with the specialized terminology which comes with it.

Now we turn to question $3, \mathrm{~d}$. The nature of the question is different, more of a projection is needed here from the participants. A list of the words most frequently used by the participants is presented in table 9 .

$75 \%$ of the respondents in population A support the idea that managers need negotiation education and training. Only 25\% concluded that everyone needs negotiation training. How representative of the Cairo Business Community is this answer? We cannot answer this question at this point.

Question 4, was the easiest one to analyze. All the respondents are unanimous in declaring their interest for negotiation education. Even prior to knowing exactly what it and how important and vital it is, yet professionals from populations A and B, confirmed their unanimous interest for negotiation, and negotiation training. Some members of population B also see the need for negotiation education for their other contacts: business partners, family, and friends. We have also found that $3 \%$ of the respondents also that recommend negotiation education be integrated earlier in education and across different disciplines. Sample of the words used by the respondents are summarized in table 10.

\section{Table (10), Words Used to Define Who is Interested in} Attending a Negotiation Training

Question Would you be interested in attending a negotiation training Words Everyone, I am, my kids, my wife, my father, my boss

\section{Population B}

While population B only represents $12 \%$ of our sample, it was interesting to dig deeper and analyze what they know of negotiation and how their education to negotiation does actually translate into their perception of situations and their application to negotiation.

Table (11), Words Used by the Respondents to Describe What they Remember From Prior Training to Negotiation

\begin{tabular}{lcl}
\hline Question & $1-$ & When? \\
& $2-$ & Where? \\
& $3-$ & Why? \\
\hline Words & $4-$ & What do you remember from the content? \\
& 2- & When? Through professional training \\
& $3-$ & Where? Off the job training \\
& $4-$ & Whyt Either required by management or offered and I took the opportunity \\
& & lose, reservation price, nice training, very useful, not much, I kept the material \\
\hline
\end{tabular}

The analysis of population B's answers to question 2 suggests that they have a knowledge of negotiation which focuses on immediate applicability and not on the wider inter and intra-organizational context, and not on the identification of different types of negotiation, such as formal and ordinary negotiation. This means, according to us, that corporate understanding of negotiation is underdeveloped and incomplete.

The overall results are very alarming and promising at the same time. We had the privilege to access a professional community that distinguishes itself by its common interest in continuous education and development. We were working with an elite of individuals who are invested in self-development. However, we noticed a severe lack of awareness of "negotiation" as a specific discipline, and a very narrow perception of who uses negotiation (top managers only). Nevertheless, we noticed a clear hunger, interest, curiosity and willingness to be enrolled in a negotiation training/education opportunity. 
Is this a translation of a real need? Or is this an expression of desiring what one does not have? Or is it an authentic expression of a profound self-struggle in life and the need to find a better way to live.

\section{Recommendations, Limitations and Avenues for Future Research}

The initial objective of this entire experiment was to defend the idea that negotiation is a life success tool, not only in business, but in all the compartments of life. We wanted specifically to address the case of those communities and countries, which do not include negotiation as part of the university and even school curriculum. The literature provides us with evidence that we are all negotiating our way through life. It also proves that negotiation is a science, a discipline that needs both theory and practice.

The fieldwork on the other hand comes to prove that until now professionals from the CBC consider negotiation to be a purely business and senior management skill. This limits the opportunity for education training to a very small share of the population, despite a huge need and clear demand.

\section{One Rrecommendation Above All: Introduce Education to Negotiation at All Levels}

Our results lead us to one recommendation only, with the potential for many impacts; introduce education to negotiation at all levels of the school and university curriculum. We aim for this to have an impact on society.

Beyond training, we also recommend to introduce education at work. Education is by definition a cycle that involves information providing, integration into practice, opportunity for practice and long-term follow up for feedback, improvement, and practice integration for reinforced results.

Negotiation at school level has found its way in international curricula in Egypt, with results that deserve high attention. In future research we would be interested in analyzing how this model has found itself in Egypt, what results it is leading to, and to which extend it is steering change. Most important if these practices came to be introduced in the rest of the schooling system, what would be required in terms of infrastructure and human resources to lead to positive results?

Negotiation at University level is still very limited to optional courses, in particular fields only: business schools, political science schools and sociology studies schools. From our experience in teaching similar courses, the demand is very high. The short-term results highlighted in our earlier publications are outstanding but the offer is very limited. (Soliman et al., 2014, 2017), More negotiation courses and opportunities to practice through mediation clinics at University level are needed.

As a conclusion, I hope the literature has proven that there is no doubt that we all negotiate at all times. That we can be better negotiators if we have benefited from a good education to negotiation. I hope the recommendations can give the Egyptian nation a better chance in managing its conflicts. In these difficult times the world is constantly creating and living for more successful personal and professional results, for a more peaceful organization and society productive performance at large.

If negotiation can make people manage conflict not only peacefully but also successfully, taking the amount of conflict we face in life, I believe our recommendations might lead to the creation of a new version of the same population, a much happier citizen.

\section{Limitations and Avenues For Future Research}

We admit that we have a number of limitations in our research that can actually create opportunities for future research to further solidify our findings. Among these limitations, it is important to acknowledge that the number of the sample population was small and that a much larger population can generate more 
solid and interesting results. The duration of the experiment if extended can also be of further value to the results. More factors could have been identified for analysis, such as participant actual conflict management styles, what kind of results, what kind of society impact, lack of negotiation knowledge on its results. Our earlier research findings confirmed that in this similar environment, Egyptian professionals that benefited from negotiation education that managed conflict differently, with an increase in self-awareness and in context awareness (Soliman et al., 2014, 2017). Following up on school negotiation curriculum is also indeed a very important society change agent that we intent to follow and study.

Furthermore, as stated in the literature review introduction, more research on negotiation curriculum is needed, across all educational levels. Questions such as: when and where to introduce negotiation? What in terms of content? What will be the best methodology for teaching negotiation? And follow-up experiments, with a focus on the response of different generations will be an important way to obtain feedback. 


\section{References:}

- $\quad$ Axelrod, Robert. (1984). The Evolution of Cooperation. HarperCollins Publisher, USA.

- $\quad$ Bazin Lynn, Urch \& Hill Rowland (2011). "von Stackelberg, Market Structure and Equilibrium": $1^{\text {st }}$ Ed. Translation into English, Springer 2011, XIV, 134 p., ISBN 978-3-642-12585-0

Blum, Robert. (2005). Best Practices: Building Blocks For Enhancing School Environment. The Deputy Undersecretary of Defense, Military Community and Family Policy Office.

- Burton, John. (1997). "Conflict Resolution: Towards Problem Solving," Peace and Conflict Studies, Vol. 4, No. 2, Article 2. Business Ethics", Journal of Business Ethics (2006) 65: 309-323

- Chittooran, Mary \& Hoenig Georgia. (2010). Peer Mediation: A Guide For Educators in Helping Children at Home and School III: Interview with the Editors. National Association of School Psychologists.

- $\quad$ Cunningham, Charles E.; Cunningham Lesly J.; Martorelli Vince; Tranm, A.; Young Julie; Zacharias Rose. (1998). “The Effects of Primary Division, Student-mediated Conflict Resolution Programs on Playground Aggression", Journal of Child Psychol. Psychiat, Vol. 39, No. 5, pp. 653-662, Cambridge University Press.

- Deutsch, Morton. (1973). The Resolution of Conflict, New Haven and London: Yale Escalation, Stalemate and Settlement. $2^{\text {nd }}$ ed., McGraw-Hill, Inc., New York.

- $\quad$ Fisher, Roger and William Ury. (1991). Getting to Yes: Negotiating Agreement Without Giving In. $2^{\text {nd }}$ ed., Publish by Penguin Group, New York.

- Gauley, Marg. (2006). Evaluation of Respectful Conflict Resolution and Peer Mediation Program. Community-University Institute for Social Research. Cumberland Avenue: Canada.

- Haft, W. S. \& Weiss, E. R. (1998). "Peer Mediation in Schools: Expectations and Evaluations", Harvard Negotiation Law Review, Vol. 3, 213-319.

- Harvard Business School Publishing Corporation. (2013). Harvard Business Essentials, Boston, Massachusetts.

- IREX. (2013). Conflict Resolution and Peer Mediation Toolkit. http://www.irex.org/project/ youth-leadership-peace.

- Kollock, Peter. (1998). "Social Dilemmas: The Anatomy of Cooperation", Annual Reviews Sociology. 1998. 24: 183-214.

- $\quad$ Lax, David et Sebenius James. (1986). The Manager as Negotiator. Collier Macmilliam, Inc., New York, Reviews Sociology. 1998. 24: 183-214.

- $\quad$ Rubin, Jeffrey; Pruitt Dean et Kim Sung. (1994). Social Conflict Escalation, Stalemate and Settlement. $2^{\text {nd }}$ ed., McGraw-Hill, Inc., New York

- Sally, David. (2004). Game Theory: Game Theory Behaves, 87 Marq. L. Rev.

- Sethi, Rajiv and Weibull Jorgen. (2016). What is Nash Equilibrium?, Notices of the American Mathematical Society, 63 (05): 526-528.

- Soliman, Cherine; Antheaume Nicolas and Arnaud Stimec. (2014). "A longitudinal Follow-up on the Impact of Training on Negotiator's Styles", Conflict Resolution Quarterly. Vol. 32, Issue 2.

- Soliman, Cherine; Antheaume Nicolas. (2016). Why and How to Promote Cooperative Negotiation in a Context of Competitive Globalization: A Review of Literature. hal-01270385.

- Soliman, C. and Antheaume, N. (2017). "Inter and Intra Organizational Negotiation During Economic Recession", Future Business Journal, Hosted by ELSEVIER. 